\title{
Oral Health and Swallowing Problems
}

\author{
Michiko Furuta $\cdot$ Yoshihisa Yamashita
}

Published online: 15 September 2013

(C) The Author(s) 2013. This article is published with open access at Springerlink.com

\begin{abstract}
Oral health impacts systemic health. Therefore, oral care is an important consideration in maintaining quality of life (QOL). Previously, maintenance and improvement of oral hygiene was considered essential for achieving oral health. In addition to oral hygiene, oral care in terms of oral function is now considered to maintain QOL. Ingestion of exogenous nutrients via the oral cavity is fundamental to the function of all higher animals, not only human beings. Chewing and swallowing processes are critical for normal food intake, and adequate saliva supply and oral care to allow proper functioning of these processes are indispensable for maintaining QOL. In this review, we will summarize the relationship between chewing and swallowing and effects of saliva secretion on these functions, and discuss methods to maintain ingestion of exogenous nutrients and prevent swallowing problems, especially in elderly people.
\end{abstract}

Keywords Tooth loss $\cdot$ Denture $\cdot$ Saliva $\cdot$ Swallowing function $\cdot$ Swallowing problems $\cdot$ Dysphagia

\section{Introduction}

Oral health is defined as "a state of being free of mouth and facial pain, oral and throat cancer, oral infection and sores, birth defects such as cleft lip and palate, periodontal (gum)

\footnotetext{
M. Furuta · Y. Yamashita ( $\square)$

Section of Preventive and Public Health Dentistry, Division of Oral Health, Growth and Development, Faculty of Dental Science, Kyushu University, 3-1-1 Maidashi, Higashi-ku, Fukuoka 812-8582, Japan

e-mail: yoshi@dent.kyushu-u.ac.jp

M. Furuta

e-mail: mfuruta@dent.kyushu-u.ac.jp
}

disease, tooth decay and tooth loss, and other diseases and disorders that limit an individual's capacity in biting, chewing, smiling, speaking, and psychosocial wellbeing [1]." In short, the most important thing is to maintain oral function in terms of biting, chewing, smiling, speaking, and psychosocial wellbeing. The most common oral health problems include oral diseases such as dental caries and periodontal disease. These diseases are highly prevalent around the world, and nearly 100 and $90 \%$ of adults have dental caries and periodontal disease, respectively $[1,2]$. To achieve oral health, reduction and prevention of these diseases is required; therefore, oral care aiming at improvement and maintenance of oral hygiene to prevent these two major dental diseases should be promoted. Recently, proper oral hygiene is also thought to be essential for maintaining and improving systemic health, especially prevention of (1) aspiration pneumonia in the frail and elderly, and (2) post-operative infections [3-5]. Various combinations of measures and purposes of oral health maintenance (oral care) are summarized in Table 1.

Both dental caries and periodontal disease are major causes of tooth loss, resulting in the fact that, in most countries, about $30 \%$ of people aged $65-74$ have no natural teeth [6]. Tooth loss reduces chewing ability. A longitudinal study showed that people who had incident of tooth loss were more likely to exhibit chewing difficulty than those without tooth loss [7]. In type III oral health maintenance, chewing is important to maintain the health condition of teeth and periodontal tissues through selfcleaning with adequate secreted saliva and mechanical stimulus on periodontal tissues. It is also thought to be closely related to swallowing, which is a part of oral function [8-11] as shown in Table 1. Furthermore, maintaining normal swallowing function in type IV oral health maintenance is important for systemic health, e.g., normal 
Table 1 Four types of combinations of measures and purposes of oral health maintenance and related diseases or health conditions

\begin{tabular}{llll}
\hline Type & Measures & Purpose & Related problems \\
\hline I & Maintaining and improving oral hygiene & Maintaining and improving oral health & $\begin{array}{l}\text { Dental caries } \\
\text { II }\end{array}$ \\
& & Maintaining and improving systemic health & $\begin{array}{l}\text { Aspiration pneumonia } \\
\text { Prevention of post-operative infection }\end{array}$ \\
\hline III & & Maintaining and improving oral health & Malocclusion \\
& Maintaining and improving oral function & & Hyposalivation \\
IV & & Maintaining and improving systemic health & Swallowing problem \\
& & & Malnutrition \\
& & & Aspiration pneumonia
\end{tabular}

nutrient ingestion and preventing aspiration pneumonia, especially in the frail elderly.

In the present review, we will discuss how to maintain optimal swallowing function through oral health promotion to prevent (1) swallowing problems, i.e., dysphagia, and (2) systemic health effects based on the concepts of type IV oral health maintenance shown in Table 1.

\section{Chewing and Swallowing}

Chewing, oral food transport, and swallowing is a continuum [10]; these processes, taken together, are often considered to represent the totality of the feeding process [12]. We coordinate the acts of chewing and intraoral food transport with swallowing $[10,11]$. The act of chewing is considered to influence the timing of food transport and swallow initiation [11].

Chewing serves several functions including breakdown of large food particles into small pieces and lubricating and softening of food particles into a bolus conducive to swallowing [13]. If the food particles already meet the internal criteria for swallowing, the particles will be simply transported towards the pharynx for swallowing [12]. Chewing occurs by the action of the teeth, masticatory muscles, temporomandibular joint, and the tongue. When food is ingested into the oral cavity, the incisors break it off and the posterior teeth grind it. The jaw and tongue move by the help of masticatory muscles for chewing. The tongue surface rises upwards and travels backward during jaw closing, and reaches its maximum superior position in the intercuspal phase $[14,15]$. As the jaw opens, the tongue surface continues to travel forwards and also downwards, to reverse its direction in relation to the maximum opening $[14,15]$. The tongue movement plays a role in collecting and transporting the food bolus from the oral cavity into the pharynx [10, 12, 14, 16].

The quality of chewing can be evaluated in terms of "masticatory performance", which is defined as the percentage of particle size distribution of food when chewed for a given number of strokes [17]. Masticatory performance reflects the capacity to reduce the size of food particles and the number of chews necessary to render food ready for swallowing $[18,19]$. It is affected by the number of teeth in functional occlusion [20-22], the maximal biting force [23, 24], and denture wearing [25]. The salivary flow rate also affects masticatory performance, which declines with a reduction in salivary secretion [13].

\section{Effect of Tooth Loss and Denture Wearing on Swallowing Problems}

\section{Effect of Tooth Loss}

Chewing ability is dependent on the number of remaining teeth [20-22]. Thus, tooth loss is expected to indirectly disturb the coordinated execution of pre-swallow and swallowing behaviors. It has been shown that elderly people with reduced numbers of functional units, defined as any opposing natural or prosthetic tooth pair, complain of difficulty in chewing and swallowing [26]. Okamoto et al. [27] investigated the relationship between the number of remaining teeth, bite force, and swallowing problems assessed by the $30-\mathrm{mL}$ water swallow test in 3,663 elderly people who were living independently. A positive correlation was observed between the number of remaining teeth and maximum bite force. They also reported that the adjusted odds ratios for $0-13$ or 14-24 remaining teeth to 25-32 remaining teeth for swallowing problems were 2.04 [95\% confidence interval (CI) 1.60-2.60)] and $1.31(95 \%$ CI 1.02-1.70), respectively.

It is believed that tooth loss influences the oral preparatory stage of swallowing. There are three main stages in deglutition: oral, pharyngeal, and esophageal stages. Furthermore, the oral stage is split into two substages: an oral preparatory stage in which a bolus is formed through mastication and positioned for transport towards the 
pharynx or the liquid bolus cupped by the tongue in readiness for transit, and an oral transit stage in which the bolus is moved back through the oral cavity for passage to the pharynx with a front-to-back squeezing action, performed primarily by the tongue [28-30]. Tooth loss decreases chewing ability and causes difficulties in forming the bolus. Bolus size was reported to increase with an increasing number of missing teeth, with larger boluses potentially interfering with optimal swallowing [31]. Moreover, in people with compromised dentition, a poorly degraded bolus was swallowed in spite of the number of chewing cycles being increased [32, 33]. A poorly degraded bolus may be difficult to transport smoothly and efficiently into the pharynx, thus leading to additional swallowing abnormalities in the oral preparatory stage.

\section{Effects of Denture Wearing}

A denture is a prosthesis that replaces one or more natural teeth. Wearing dentures in order to maintain appropriate mandible position and proper occlusion has been proposed as important for smooth swallowing in elderly individuals [34]. Fukai et al. [35] investigated the relationship between the number of functional teeth (defined as the teeth with functionally adequate mastication), denture use, and subjective swallowing problems in 5,643 residents aged 40-89 years. Subjective swallowing problems were selfassessed by reporting any kind of subjective impairment to eating function such as biting difficulty, swallowing difficulty caused by tooth loss, no fitted dentures, or other oral impairments. They concluded that residents with fewer functional teeth or no denture use were likely to have subjective swallowing problems, and suggested that, even if people have few teeth, denture wearing contributes to prevention of swallowing problems.

We examined the relationship between the number of teeth, denture wearing, and swallowing function in 286 elderly people aged 60 years and older (mean age $84.5 \pm 7.9$ years) living at home and receiving home care services [36••]. In this study, swallowing function was examined by cervical auscultation, a non-invasive method of listening with a stethoscope to the sounds of swallowing $3 \mathrm{~mL}$ of water during the pharyngeal phase, based on the method of Zenner et al. [37] with minor modifications. When breath sounds after swallowing material were clear, we considered swallowing function normal. When stridor, coughing, or throat clearing was heard after swallowing material or when swallowing was repeated, we evaluated this as impaired swallowing function (i.e. swallowing disorder or dysphagia). Swallowing impairments were found in $31.1 \%$ of all participants. When the oral health status was categorized as 20 or more teeth with dentures, swallowing problem was found in $20.0 \%$ of those who had $\geq 20$ teeth with dentures, $26.5 \%$ of those who had $\geq 20$ teeth without dentures, $30.0 \%$ of those who had 0-19 teeth with dentures, $38.9 \%$ of those who had 0-19 teeth without dentures, $27.5 \%$ of those who had 0-9 teeth with dentures, and $57.7 \%$ of those who had 0-9 teeth without dentures. Additionally, when the effect of denture wearing on swallowing function in edentulous persons was examined, 10 of 15 edentates without dentures $(66.7 \%)$ had difficulty swallowing, as did 29 of 101 edentates with dentures $(28.7 \%)$. A previous study reported that laryngeal penetration, usually due to neuromuscular disorder, occurs with much greater frequency in edentulous elderly people who are not wearing dentures than in dentate subjects, but laryngeal penetration was reduced in edentulous elderly people when wearing dentures [38]. Although the potential effect of laryngeal penetration on health is unclear, it has been described that laryngeal penetration occurs when the coordinated movements of swallowing cannot continue due to some interference [29].

While some studies [34-36••, 38-40] have suggested that denture wearing had positive effects on swallowing function, conversely, one study [41] indicated that denture wearing may have negative effects on swallowing function, especially the oral transit time (OTT) and oropharyngeal swallow efficiency (OPSE). OTT is the time from the moment at which the major bolus in the oral cavity begins to move rearwards to the moment at which the front end of the bolus arrives at the point of crossing between the lower edge of mandibular ramus and the tongue base. OPSE is the value obtained by dividing the fraction of bolus swallowed through the esophagus by the total time taken to pass the oropharynx, and aspiration is the passing of food through the vocal fold [42]. Son et al. [41] showed that OTTs were shortened and OPSE increased when dentures were removed compared to when dentures were worn. They discussed that the delay in OTTs and the decreases in OPSE observed after dentures were worn might be considered attributable to changes in masticatory performance or sensation within the oral cavity due to denture wearing. However, it seems that this finding might be influenced by the quality of denture, which they did not assess. Wearing ill-fitting dentures, particularly in the case of a complete denture, may interfere with achieving sufficient occlusal contact. Insufficient occlusal contact reduces masticatory performance and causes impairment of swallowing activity.

Two studies have shown that the quality of the denture influenced swallowing function. Monaco et al. [43•] investigated whether an ill-fitting denture increases swallowing duration time in elderly people using surface electromyography, which assesses certain aspects of complex muscle activity in deglutition. Swallowing duration ranges from 0.80 to $1.60 \mathrm{~s}$ [44, 45], and this normal duration is achieved by 12 years of age. Swallowing duration range 
does not change significantly until 70 years of age and increases after that [46-49]. They found that the mean swallowing time in participants with old, poorly fitting dentures was $1.84 \mathrm{~s}$, while new, properly fitting dentures

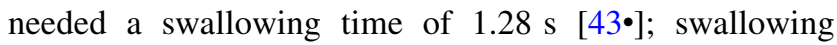
duration with ill-fitting dentures was significantly longer than with properly fitting dentures. They suggested that the quality of the denture is more important in the impairment of swallowing duration than individual neuromuscular efficiency and ageing [43•]. In addition, Yoshida et al. [39] examined rehabilitation hospital inpatients whose old dentures were adjusted by repairing or relining on the day of the study and showed that pharyngeal transit time was shorter when wearing dentures than when not wearing dentures. Because prolongation of pharyngeal transit time increases the risk of aspiration [50, 51], repair of ill-fitting dentures may decrease the risk of aspiration. Future studies investigating the effect of wearing denture on swallowing function should consider the quality of the denture and examine further interventions, as most studies employed cross-sectional designs.

Wearing dentures in those who have lost teeth may have a beneficial effect on not only swallowing function but also cognitive function. One cohort study showed that men who had inadequate natural masticatory without wearing dentures had a $91 \%$ greater risk of dementia than those with adequate natural mastication [52]. Retaining adequate masticatory function through maintaining and improving oral hygiene and oral function (e.g., oral care and use of dentures) may reduce both swallowing problem and risk of dementia.

\section{Effect of Saliva Secretion on Swallowing Problem}

Functions of saliva include cleansing of oral cavity, solubilization of food substances, bolus formation, facilitation of mastication and swallowing, food and bacterial clearance, dilution of detritus, lubrication of mucosa, and facilitation of speech [13]. Decrease in saliva secretion (i.e. dry mouth, or xerostomia) is frequently accompanied by swallowing problems and is common in elderly people [53], with incidence ranging from $20 \%$ to as high as $60 \%$ [54-58]. The dryness of the mouth affects both the oral preparatory and oral phases of swallowing, and can lead to impaired bolus formation and oropharyngeal bolus transport [59]. Additionally, severe dental diseases such as dental caries and periodontal diseases which result in decreased saliva secretion can lead to pain and impair food preparation [60].

Considering the role of saliva for swallowing, swallowing disorders in people with dry mouth can be managed with oral moisturizers, lubricants, and careful use of fluids during eating [56]. Intrinsically, increasing salivary flow may help them swallow smoothly. Kakudate et al. [61] reported that elderly people with tooth brushing frequency less than twice per day were more likely to have dry mouth. Additionally, Papas et al. [62] showed that tooth brushing increased salivary flow in people with medication-induced dry mouth. It is suggested that tooth brushing may activate impulses to both major and minor residual salivary tissues following stimulation of oral and pharyngeal regions, causing salivation [62, 63]. In other words, mechanical stimulation of the salivary glands during tooth brushing can promote the discharge of saliva [61]. It is considered that tooth brushing helps to maintain and improve not only oral hygiene but also oral function through an increased salivary flow rate. However, we need to consider the possibility of developing a more effective method for mechanical stimulation of salivary glands than tooth brushing.

On the other hand, an excessive production of saliva (hypersalivation) may produce swallowing problems caused by aspiration of saliva [64]. Hypersalivation is induced by inflammation in the oral-pharyngeal regions, neurological disorders such as Parkinson's disease and epilepsy, or medicine such as pilocarpine and cholinesterase [65]. In particular, neurological disorders results in swallowing problem and leads to excessive pooling of saliva in the oral cavity and the unintentional loss of saliva from the mouth, i.e. drooling of saliva [66]. Drooling can impair masticatory function [66], and thus it may cause a vicious cycle of swallowing problems. Since reduced or increased salivary secretions leads to swallowing problems, suitable amounts of saliva would retain normal swallowing function.

\section{Oral Care for Swallowing Disorders}

Yoneyama et al. [4] demonstrated that oral care comprising maintenance and improvement of oral hygiene reduced the risk of pneumonia in older patients receiving nursing care. However, maintenance and improvement of oral hygiene may not be enough to achieve good oral health; the contribution of oral function to oral health should also be considered. Normal swallowing is closely related to chewing ability with normal dentition and ample saliva secretion $[11,13,59,60]$. Healthy chewing and swallowing may prevent a decline in performing the basic activities of daily living. Recently, we revealed that tooth loss was directly related to deterioration of swallowing function and subsequently to the ability of nutritional intake and then to the basic activities of daily living [36••]. These findings indicate that oral care, provision of dentures, prevention of tooth loss by treatment for dental caries or periodontal disease, and swallowing training may have positive effects on general health in frail older people. 
Table 2 Swallowing problems and oral care-related factors

\begin{tabular}{|c|c|c|c|}
\hline & $\begin{array}{l}\text { Normal } \\
(n=165)\end{array}$ & $\begin{array}{l}\text { Swallowing } \\
\text { problems } \\
(n=76)\end{array}$ & $p$ value \\
\hline Oral care & & & 0.951 \\
\hline Do & $156(94.5)$ & $72(94.7)$ & \\
\hline Do not & $9(5.5)$ & $4(5.3)$ & \\
\hline Independence in oral care ${ }^{\mathrm{a}}$ & & & $<0.001$ \\
\hline Yes & $125(80.1)$ & $41(56.9)$ & \\
\hline No (dependent) & $31(19.9)$ & $31(43.1)$ & \\
\hline Refusal of oral care ${ }^{a}$ & & & 0.014 \\
\hline No & $150(96.2)$ & $63(87.5)$ & \\
\hline Yes & $6(3.8)$ & $9(12.5)$ & \\
\hline \multicolumn{4}{|l|}{ Oral care-related factors } \\
\hline Tube feeding & & & 0.010 \\
\hline No & $165(100.0)$ & $73(96.1)$ & \\
\hline Yes & $0(0.0)$ & $3(3.9)$ & \\
\hline Seated posture & & & $<0.001$ \\
\hline Possible & $165(100.0)$ & $66(86.8)$ & \\
\hline Impossible & $0(0.0)$ & $10(13.2)$ & \\
\hline Cervical movement & & & $<0.001$ \\
\hline Possible & $163(98.8)$ & $62(81.6)$ & \\
\hline Impossible & $2(1.2)$ & $14(18.4)$ & \\
\hline Keeping jaw open & & & 0.007 \\
\hline Possible & $161(97.6)$ & $68(89.5)$ & \\
\hline Impossible & $4(2.4)$ & $8(10.5)$ & \\
\hline Holding water in oral cavity & & & $<0.001$ \\
\hline Possible & $160(97.0)$ & $58(76.3)$ & \\
\hline Impossible & $5(3.0)$ & $18(23.7)$ & \\
\hline Gargling & & & $<0.001$ \\
\hline Possible & $152(92.1)$ & $50(65.8)$ & \\
\hline Impossible & $13(7.9)$ & $26(34.2)$ & \\
\hline
\end{tabular}

$n(\%)$, Chi square test or Fisher's exact test

${ }^{\text {a }}$ Participants who perform oral care, $n=228$

On the other hand, people with swallowing problems, especially elderly people having physical disabilities, appear to be at increased risk of poor oral health, for example, because of an inability to chew because of few remaining teeth or wearing ill-fitting dentures. While oral care is needed to maintain and improve oral health, people with swallowing problems may have difficulty in performing oral care. When we investigated the relationship between oral care and swallowing problems in 231 participants aged 60 years or older who received home nursing care [36••], people with swallowing problems were more likely to fail in maintaining seated posture, cervical movement, keeping the jaw open, holding water in the oral cavity, and gargling compared to those with normal swallowing function (Table 2). As people with swallowing problems had more severe cognitive impairment and more malnutrition than those with normal swallowing ability, they participated in fewer activities of daily living; in other words, they had physical disabilities. Therefore, it was likely that they had trouble receiving oral care. However, if adequate oral care is not provided, not only oral health but also the general health including swallowing will steadily worsen. In cases of difficulty in providing oral care, oral care with management of the swallowing problems by the coordinated expertise of a number of health care professionals might be effective.

\section{Conclusion}

Swallowing problems closely related to poor oral health have a negative impact on the quality of life of those suffering from them. Preventing tooth loss, wearing properly fitting dentures when teeth cannot be saved, and promoting normal saliva secretion may provide beneficial effects on swallowing function and subsequently on the maintenance and improvement of systemic health. It is suggested that oral care plays an important role in maintaining and improving not only oral health but also systemic health.

Acknowledgments This study was supported by Grants-in-Aid of Scientific Research (25670894) from the Ministry of Education, Science, Sports, and Culture of Japan, Tokyo, Japan.

\section{Compliance with Ethics Guidelines}

Conflict of Interest M. Furuta and Y. Yamashita declare no conflicts of interest.

Human and Animal Rights and Informed Consent This article contains the study and Ref. [36••] with human subjects performed by the authors. Informed consent was obtained from subjects according to the Approval from Kyushu University Institutional Review Board for Clinical Research.

Open Access This article is distributed under the terms of the Creative Commons Attribution License which permits any use, distribution, and reproduction in any medium, provided the original author(s) and the source are credited.

\section{References}

Papers of particular interest, published recently, have been highlighted as:

- Of importance,

- Of major importance

1. World Health Organization: Oral health. Available at http://www. who.int/mediacentre/factsheets/fs318/en/index.html. Accessed March 2013.

2. Pihlstrom BL, Michalowicz BS, Johnson NW. Periodontal diseases. Lancet. 2005;366:1809-20.

3. Marik PE, Kaplan D. Aspiration pneumonia and dysphagia in the elderly. Chest. 2003;124:328-36. 
4. Yoneyama T, Yoshida M, Ohrui T, et al. Oral care reduces pneumonia in older patients in nursing homes. J Am Geriatr Soc. 2002;50:430-3.

5. Sato J, Goto J, Harahashi A, et al. Oral health care reduces the risk of postoperative surgical site infection in inpatients with oral squamous cell carcinoma. Support Care Cancer. 2011;19:409-16.

6. Petersen PE. The World Oral Health Report 2003: continuous improvement of oral health in the 21 st century-the approach of the WHO Global Oral Health Programme. Community Dent Oral Epidemiol. 2003;31(Suppl 1):3-23.

7. Gilbert GH, Meng X, Duncan RP, Shelton BJ. Incidence of tooth loss and prosthodontic dental care: effect on chewing difficulty onset, a component of oral health-related quality of life. J Am Geriatr Soc. 2004;52:880-5.

8. Alexander AG, Morganstein SI, Ribbons JW. A study of the growth of plaque and the efficiency of self-cleansing mechanisms. Dent Pract Dent Rec. 1969;19:293-7.

9. Kikutani T, Tamura F, Nishiwaki K, et al. The degree of tonguecoating reflects lingual motor function in the elderly. Gerodontology. 2009;26:291-6.

10. Palmer JB, Rudin NJ, Lara G, Crompton AW. Coordination of mastication and swallowing. Dysphagia. 1992;7:187-200.

11. Saitoh E, Shibata S, Matsuo K, et al. Chewing and food consistency: effects on bolus transport and swallow initiation. Dysphagia. 2007;22:100-7.

12. Thexton AJ. Mastication and swallowing: an overview. Br Dent J. 1992;173:197-206.

13. Pedersen AM, Bardow A, Jensen SB, Nauntofte B. Saliva and gastrointestinal functions of taste, mastication, swallowing and digestion. Oral Dis. 2002;8:117-29.

14. Palmer JB, Hiiemae KM, Liu J. Tongue-jaw linkages in human feeding: a preliminary videofluorographic study. Arch Oral Biol. 1997;42:429-41.

15. Hiiemae K. Mechanisms of food reduction, transport and deglutition: how the texture of food affects feeding behavior. J Texture Stud. 2004;35:171-200.

16. Taniguchi $\mathrm{H}$, Tsukada $\mathrm{T}$, Ootaki $\mathrm{S}$, et al. Correspondence between food consistency and suprahyoid muscle activity, tongue pressure, and bolus transit times during the oropharyngeal phase of swallowing. J Appl Physiol. 2008;105:791-9.

17. Manly RS, Braley LC. Masticatory performance and efficiency. J Dent Res. 1950;29:448-62.

18. Mowlana F, Heath MR, Van der Bilt A, Van der Glas HW. Assessment of chewing efficiency: a comparison of particle size distribution determined using optical scanning and sieving of almonds. J Oral Rehabil. 1994;21:545-51.

19. Chauncey HH, Muench ME, Kapur KK, Wayler AH. The effect of the loss of teeth on diet and nutrition. Int Dent J. 1984;34: 98-104.

20. Helkimo E, Carlsson GE, Helkimo M. Chewing efficiency and state of dentition. A methodologic study. Acta Odontol Scand. 1978;36:33-41.

21. Akeel R, Nilner M, Nilner K. Masticatory efficiency in individuals with natural dentition. Swed Dent J. 1992;16:191-8.

22. Naka O, Anastassiadou V, Pissiotis A. Association between functional tooth units and chewing ability in older adults: a systematic review. Gerodontology. 2012. doi:10.1111/ger.12016.

23. Tate GS, Throckmorton GS, Ellis E 3rd, Sinn DP. Masticatory performance, muscle activity, and occlusal force in preorthognathic surgery patients. J Oral Maxillofac Surg. 1994;52: 476-81.

24. Fontijn-Tekamp FA, Slagter AP, Van Der Bilt A, et al. Biting and chewing in overdentures, full dentures, and natural dentitions. J Dent Res. 2000;79:1519-24.

25. Kapur K, Soman S. Masticatory performance and efficiency in denture wearers. J Prosthet Dent. 1964;14:687-94.
26. Hildebrandt GH, Dominguez BL, Schork MA, Loesche WJ. Functional units, chewing, swallowing, and food avoidance among the elderly. J Prosthet Dent. 1997;77:588-95.

27. Okamoto N, Tomioka K, Saeki K, et al. Relationship between swallowing problems and tooth loss in community-dwelling independent elderly adults: the Fujiwara-kyo study. J Am Geriatr Soc. 2012;60:849-53.

28. Dodds WJ, Stewart ET, Logemann JA. Physiology and radiology of the normal oral and pharyngeal phases of swallowing. AJR Am J Roentgenol. 1990;154:953-63.

29. Logemann JA. Evaluation and treatment of swallowing disorders. 2nd ed. Austin: Pro-Ed; 1998.

30. Kahrilas PJ, Lin S, Logemann JA, et al. Deglutitive tongue action: volume accommodation and bolus propulsion. Gastroenterology. 1993; 104:152-62.

31. Mishellany A, Woda A, Labas R, Peyron MA. The challenge of mastication: preparing a bolus suitable for deglutition. Dysphagia. 2006;21:87-94.

32. Feldman RS, Kapur KK, Alman JE, Chauncey HH. Aging and mastication: changes in performance and in the swallowing threshold with natural dentition. J Am Geriatr Soc. 1980;28: 97-103.

33. Wayler AH, Chauncey HH. Impact of complete dentures and impaired natural dentition on masticatory performance and food choice in healthy aging men. J Prosthet Dent. 1983;49:427-33.

34. Tamura F, Mizukami M, Ayano R, Mukai Y. Analysis of feeding function and jaw stability in bedridden elderly. Dysphagia. 2002;17:235-41.

35. Fukai K, Takiguchi T, Ando Y, et al. Critical tooth number without subjective dysphagia. Geriatr Gerontol Int. 2011;11:482-7.

36. •• Furuta M, Komiya-Nonaka M, Akifusa S, et al. Interrelationship of oral health status, swallowing function, nutritional status, and cognitive ability with activities of daily living in Japanese elderly people receiving home care services due to physical disabilities. Community Dent Oral Epidemiol. 2013;41:173-181. This study shows that people having fewer teeth without dentures have difficulty swallowing. The article provides evidence that oral health affects swallowing function.

37. Zenner PM, Losinski DS, Mills RH. Using cervical auscultation in the clinical dysphagia examination in long-term care. Dysphagia. 1995;10:27-31.

38. Yoshikawa M, Yoshida M, Nagasaki T, et al. Influence of aging and denture use on liquid swallowing in healthy dentulous and edentulous older people. J Am Geriatr Soc. 2006;54:444-9.

39. Yoshida M, Masuda S, Amano J, Akagawa Y. Immediate effect of denture wearing on swallowing in rehabilitation hospital inpatients. J Am Geriatr Soc. 2013;61:655-7.

40. Gokce HS, Gokce SM, Akin E, et al. Effect of complete denture wearing on deglutition time: a cine-magnetic resonance imaging study. J Oral Rehabil. 2012;39:198-209.

41. Son DS, Seong JW, Kim Y, et al. The effects of removable denture on swallowing. Ann Rehabil Med. 2013;37:247-53.

42. Hwang $\mathrm{CH}$, Choi KH, Ko YS, Leem CM. Pre-emptive swallowing stimulation in long-term intubated patients. Clin Rehabil. 2007;21:41-6.

43. - Monaco A, Cattaneo R, Masci C, et al. Effect of ill-fitting dentures on the swallowing duration in patients using polygraphy. Gerodontology. 2012;29:e637-44. This article indicates the need to assess the quality of dentures in examining the relationship between wearing dentures and swallowing function.

44. Wilson EM, Green JR. Coordinative organization of lingual propulsion during the normal adult swallow. Dysphagia. 2006;21:226-36.

45. Moriniere S, Beutter P, Boiron M. Sound component duration of healthy human pharyngoesophageal swallowing: a gender comparison study. Dysphagia. 2006;21:175-82. 
46. Vaiman M, Eviatar E, Segal S. Evaluation of normal deglutition with the help of rectified surface electromyography records. Dysphagia. 2004;19:125-32.

47. Crary MA, Carnaby Mann GD, Groher ME. Biomechanical correlates of surface electromyography signals obtained during swallowing by healthy adults. J Speech Lang Hear Res. 2006;49: 186-93.

48. Vaiman M, Segal S, Eviatar E. Surface electromyographic studies of swallowing in normal children, age 4-12 years. Int J Pediatr Otorhinolaryngol. 2004;68:65-73.

49. Vaiman M, Eviatar E, Segal S. Surface electromyographic studies of swallowing in normal subjects: a review of 440 adults. Report 3. Qualitative data. Otolaryngol Head Neck Surg. 2004;131:977-85.

50. Hiiemae KM, Palmer JB. Food transport and bolus formation during complete feeding sequences on foods of different initial consistency. Dysphagia. 1999;14:31-42.

51. Leonard R, McKenzie S. Hyoid-bolus transit latencies in normal swallow. Dysphagia. 2006;21:183-90.

52. Paganini-Hill A, White SC, Atchison KA. Dentition, dental health habits, and dementia: the Leisure World Cohort Study. J Am Geriatr Soc. 2012;60:1556-63.

53. Cook IJ, Kahrilas PJ. AGA technical review on management of oropharyngeal dysphagia. Gastroenterology. 1999;116:455-78.

54. Borges BC, Fulco GM, Souza AJ, de Lima KC. Xerostomia and hyposalivation: a preliminary report of their prevalence and associated factors in Brazilian elderly diabetic patients. Oral Health Prev Dent. 2010;8:153-8.

55. Murray Thomson W, Chalmers JM, John Spencer A, et al. A longitudinal study of medication exposure and xerostomia among older people. Gerodontology. 2006;23:205-13.

56. Ship JA, Pillemer SR, Baum BJ. Xerostomia and the geriatric patient. J Am Geriatr Soc. 2002;50:535-43.
57. So JS, Chung SC, Kho HS, et al. Dry mouth among the elderly in Korea: a survey of prevalence, severity, and associated factors. Oral Surg Oral Med Oral Pathol Oral Radiol Endod. 2010; 110:475-83.

58. Thomson WM. Issues in the epidemiological investigation of dry mouth. Gerodontology. 2005;22:65-76.

59. Liedberg B, Owall B. Masticatory ability in experimentally induced xerostomia. Dysphagia. 1991;6:211-3.

60. Hughes CV, Fox PC, Marmary Y, et al. Oral-pharyngeal dysphagia: a common sequela of salivary gland dysfunction. Dysphagia. 1987;1:173-7.

61. Kakudate N, Muramatsu T, Endoh M, et al. Factors associated with dry mouth in dependent Japanese elderly. Gerodontology. 2012. doi:10.1111/j.1741-2358.2012.00685.x.

62. Papas A, Singh M, Harrington D, et al. Stimulation of salivary flow with a powered toothbrush in a xerostomic population. Spec Care Dentist. 2006;26:241-6.

63. Talal N, Quinn JH, Daniels TE. The clinical effects of electrostimulation on salivary function of Sjogren's syndrome patients. A placebo controlled study. Rheumatol Int. 1992;12:43-5.

64. Bai YM, Lin CC, Chen JY, Liu WC. Therapeutic effect of pirenzepine for clozapine-induced hypersalivation: a randomized, double-blind, placebo-controlled, cross-over study. J Clin Psychopharmacol. 2001;21:608-11.

65. Llena-Puy C. The role of saliva in maintaining oral health and as an aid to diagnosis. Med Oral Patol Oral Cir Bucal. 2006;11: E449-55.

66. Meningaud JP, Pitak-Arnnop P, Chikhani L, Bertrand JC. Drooling of saliva: a review of the etiology and management options. Oral Surg Oral Med Oral Pathol Oral Radiol Endod. 2006;101:48-57. 